\title{
Modeling the bacterial contribution to planktonic community respiration in the regulation of solar energy and nutrient
} availability

\author{
Maryam Khajeh Alijani and Hao Wang \\ Department of Mathematical and Statistical Sciences, University of Alberta, Edmonton, Canada \\ and \\ James J. Elser \\ School of Life Sciences, Arizona State University, Tempe, Arizona, USA
}

May 9, 2015

\begin{abstract}
In planktonic ecosystems, algae and bacteria exhibit complex interrelationships, as algae provide an important organic matter source for microbial growth while microbial metabolism recycles limiting nutrients for algae in a loose commensalism. However, algae and bacteria can also compete for available nutrients if supplies of organic matter are sufficient to satisfy bacterial demand. We developed a stoichiometrically explicit model of bacteria-algae interactions that incorporated realistic assumptions about algal light and nutrient utilization, algal exudation of organic matter, and bacterial processing of organic matter and nutrients. The model makes specific predictions about how the relative balance of algae and bacteria should change in response to varied nutrient and light availability seen in lakes and oceans. The model successfully reproduces published empirical data and indicates that, under moderate nutrient supply, the bacterial percentage of total respiration should be maximal at intermediate light intensity.
\end{abstract}

Key words: stoichiometry, light, phosphorus, carbon, bacteria, algae, respiration. 


\section{Introduction}

The absolute and relative supplies of solar energy and key nutrients, such as phosphorus and nitrogen, are critical in determining the biomass and species composition of ecological communities and in driving ecosystem processes such as trophic transfer and nutrient sequestration $[35,37]$. In pelagic ecosystems, algae and photosynthetic cyanobacteria (collectively, "phytoplankton" in the following) grow in open water by taking up inorganic nutrients such as phosphorus (as phosphate) and nitrogen (as ammonia or nitrate) from the water and capturing energy from sunlight. Phytoplankton coexist in pelagic food webs with heterotrophic bacteria, whose role in nutrient cycling has generally been thought to be that of "remineralizers", in which they return organically-bound nutrients for re-uptake by phytoplankton. However, it is increasingly recognized that the interaction between bacteria and algae in pelagic ecosystems is more complex [8], as bacteria are nutrient-rich organisms and often represent short-term nutrient sinks in competition with phytoplankton for limiting nutrients [38]. This occurs especially when bacterial energetic demands are satisfied, a condition that interacts in complex ways with the nutritional status of the phytoplankton themselves. For example, it is well-known that nutrient-limited phytoplankton increase their exudation of excess fixed energy in the form of dissolved organic carbon (DOC; Figure 1) that is readily available to bacteria. Thus, it is likely that bacteria and algae often compete with each other for key limiting nutrients such as phosphorus [21].

In general, it has been observed that bacteria have high relative abundances in planktonic communities in oligotrophic waters while algae are more predominant in eutrophic waters, as bacterial biomass appears to increase more slowly than algal biomass with increasing nutrient levels [8]. However, the mechanisms behind such shifts are unclear. To help understand the complex and changing relationships between algae and bacteria, Sterner et al. [35] proposed the "light:nutrient hypothesis". They proposed that, in ecosystems with high light:nutrient ratios, phytoplankton fix and exude relatively more labile organic carbon, thus increasing organic carbon flux to the bacteria, relieving their $\mathrm{C}$ limitation and inducing nutrient $(\mathrm{P})$ limitation. In turn, this would increase the bacteria:phytoplankton ratio. In contrast, at low light:nutrient ratios, phytoplankton have more balanced C:P metabolism and do not exude as much labile organic carbon. Thus, bacteria remain energy-limited, readily recycle nutrients, and the bacteria:phytoplankton ratio would be relatively low. This hypothesis has been tested via various laboratory and field studies. 
For example, Gurung et al. [20] cultured bacteria and phytoplankton under different combination of light levels and total $\mathrm{P}$ concentrations. At low light intensities $<25 \mu \mathrm{E} / \mathrm{m}^{2} \mathrm{~s}$, the density of algae in the semi-batch cultures was relatively low regardless of supply of $\mathrm{P}$ because of low photosynthetic activity. At high light intensities $>25 \mu E / m^{2} s, \mathrm{P}$ supply was the primary factor affecting algal growth. In parallel with algae density, increasing light intensity and $\mathrm{P}$ supply rate increased bacterial density. At low light intensities, bacterial density was low regardless of $\mathrm{P}$ supply rate due to low production of organic $\mathrm{C}$ by algae. Thus, at low light intensities both algae and bacteria were energy-limited and their relationship was commensalism because bacterial growth rate depended on DOC produced and released from algae but algae were themselves not dependent on microbial $\mathrm{P}$ mineralization. When $\mathrm{P}$ supply rate was very low relative to light intensity, bacterial growth was more limited by $\mathrm{C}$ than P. Although bacterial growth was C-limited, the very low $\mathrm{P}$ supply indirectly limited bacterial density via a decrease in the supply of DOC from algae. At high light intensity, a slight shift from low $\mathrm{P}$ supply rate favored algae. Thus, increased algal biomass was accompanied by increase in DOC which relieved bacteria from $\mathrm{C}$ limitation while $\mathrm{P}$ limitation was most intense at moderate $\mathrm{P}$ supply rate $(P=0.25 \mu M P)$ which resulted in a competitive interaction between bacteria and algae. Further increase in $\mathrm{P}$ supply rate weakened the competition for $\mathrm{P}$ between algae and bacteria. Overall these results demonstrate that there is shift between a C-based commensalism to competition for $\mathrm{P}$ depending on nutrient supply and light intensity. Similarly, Grover [18] considered two microbial communities grown in chemostats receiving a low supply of phosphorus and different supplies of organic carbon. One community was a natural assemblage of lake plankton and the other was a model community composed of cultured organisms. The experiments tested theoretical predictions of how organic carbon:inorganic nutrient supply ratios affect bacterial and algal densities $[3,36]$. The experiments supported the predictions that, as organic carbon:inorganic phosphorus supply ratio increases, (i) concentration of DOC increases; (ii) concentration of inorganic P decreases; (iii) algae decrease in abundance; and (iv) bacteria increase in abundance. Taken all together, these results support hypotheses that a high light:nutrient supply ratio will relieve C-limitation of bacterial growth, allowing them to deplete inorganic $\mathrm{P}$ to levels at which algae cannot replace themselves. Thus, algae and bacteria become simultaneously P-limited and compete. With P-limitation of bacterial growth, unconsumed DOC accumulates. Hence, at hight light:nutrient supply ratios, bacteria switch from Cto P-limitation and become superior competitors for inorganic P. 
Overall, a large amount of empirical work $[8,9,10,15,16,18,20,33]$ has documented the relative abundances of bacteria and phytoplankton as a function of light and/or nutrients. Thus, it is feasible to construct a mathematical model to examine this issue comprehensively. We report here the results of simulation experiments involving a stoichiometric model of phytoplanktonbacteria interactions derived in Wang et al. [40].

In this paper we use this model to examine the joint roles of nutrient inputs and light intensity in regulating the structure and function of phytoplankton-bacteria systems, considering two models describing open systems (e.g. lakes or ponds) and closed (closed nutrient) systems (e.g. microcosms) and comparing these to published empirical data of Roberts and Howarth [33]. Given a fixed ratio of bacteria:algae respiration loss per unit biomass, the relative contribution to planktonic community respiration is proportional to the relative abundance of planktonic community.

Understanding the changes in the planktonic community composition will allow us to improve projections of the impacts of climate change in aquatic ecosystems. Global climate change includes rising $\mathrm{CO}_{2}$ and global warming. Human activities significantly change the global cycles of several essential elements [34, 39]. Fertilizing soil disproportionately with nitrogen (N), phosphorus $(\mathrm{P})$, and potassium $(\mathrm{K})$ to get more agricultural yields and burning fossil-fuel which adds $\mathrm{N}$ and sulphur (S) through atmospheric deposition all together cause increases in $\mathrm{CO}_{2}$. This increase generally stimulates photosynthesis and enhances plant growth. Furthermore, increased photosynthesis can put increased demand on plants for P but decreased demand for N. In addition, at higher concentration of $\mathrm{CO}_{2}$, this gas diffuses into leaves more easily which enables plants to narrow stomatal apertures, thus consequently to lose less water, that means to decrease respiration [28]. Projected increases in water temperature enhance permafrost thawing and it is very likely to affect the structural and functional dynamics of the microbial food web and are likely to increase rates of carbon processing. The principal role of microbial food web is degradation of organic matter. Hence, the microbial food web is a significant source of energy to plankton, being mainly responsible for recycling nutrients. Thus, nutrient and carbon enrichment will enhance productivity and nutrient cycling in the water column [41]. More general climate change can include other factors such as light intensity shift over seasons and change of nutrient contents in rainfall, thus our theoretical study on the structure of planktonic community can also be directly relevant to climate change. 


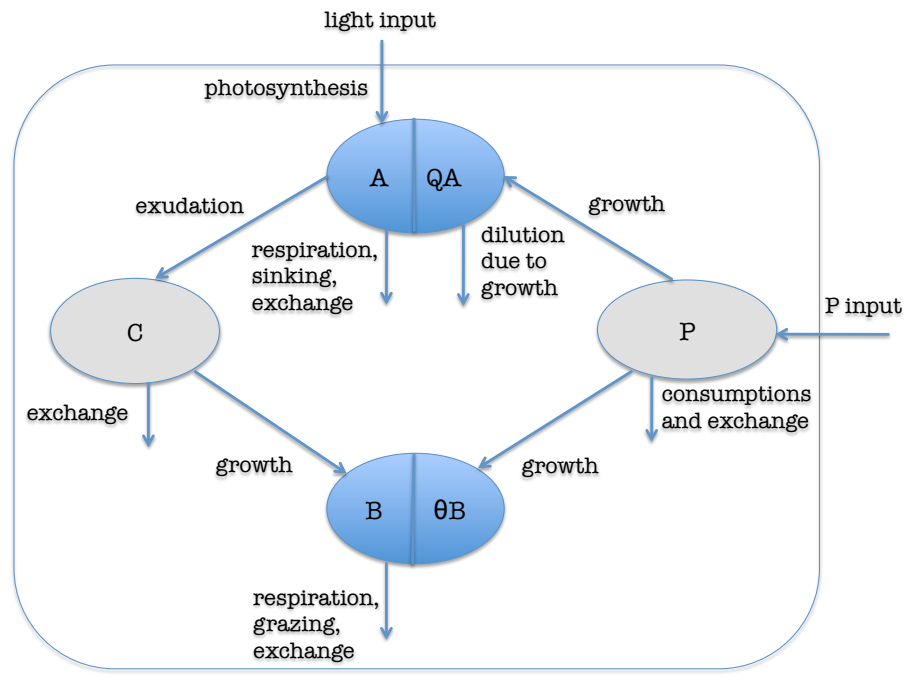

Figure 1: A scheme for the relation between bacteria and algae for an open system. The mathematical model A1 (Wang et al. [40]) was constructed following this network. (Dissolved) inorganic phosphorus is the nutrient to support algal growth. Bacteria require inorganic phosphorus and organic carbon for their growth. Organic carbon is exuded by algae through photosynthesis. The terms $\theta B$ and $Q A$ represent the amount of $\mathrm{P}$ in bacteria and algae biomasses, respectively.

\section{Model Background}

Our model is based on recent efforts in the field of ecological stoichiometry, the study of the balance of energy and multiple chemical elements in ecological systems [34]. In this approach, it is recognized that the biomass growth is a process of selectively transferring certain chemical elements from resource pools to form the stoichiometrically constrained biomass of the consumer. Mathematical models readily capture these ubiquitous stoichiometric constraints for modelling species growth and interactions $[19,26,27,29]$. In this paper we develop a stoichiometrically explicit model of phytoplankton-bacteria interaction to capture key interrelations that might be seen in a temperate lake in which the water column is seasonally separated by a thermocline into two parts, the epilimnion and the hypolimnion. The epilimnion is the well-mixed and well-illuminated but often nutrient-deficient warmer layer overlying the colder, darker, and more nutrient-rich hypolimnion.

Algal dynamics in such systems have been modeled by many researchers [1, 11, 12, 23, 24, 25], however, fewer studies have directly modeled bacteria and algae interaction in a common frame- 
work (but see an early attempt from Bratbak and Thingstad [3]). The bacteria-algae interaction in the epilimnion was modeled in Wang et al. [40] under a "well-mixed" assumption [1, 23, 24]. This model, motivated by the "light:nutrient hypothesis" [35] and by the experiments and hypotheses of Nishimura et al. [31], can be viewed as an extension as well as a variation of the work of Diehl et al. [12], who also modeled algal growth experiments subject to varying light and nutrient availability but without bacteria. A unique aspect of our model is that it explicitly includes nutrient-dependent exudation of DOC by phytoplankton.

Here we extend the analysis of the model in Wang et al. [40], model A1, which consists of five interconnected nonlinear differential equations (see Figure 1), tracking the rates of change for algal abundance, algal cell quota, (dissolved) inorganic phosphorus concentration, heterotrophic bacterial abundance, and dissolved organic carbon concentration. Phytoplankton growth was assumed to depend on both light intensity and phosphorus availability via the Lambert-Beer law [23] and the Droop equation [13, 14]. The algal carbon uptake function takes the Monod form [12]. Algal sinking and water exchange between the epilimnion and the hypolimnion were also included in the model [22]. Algal sinking takes place at the interface between epilimnion and hypolimnion, and its rate is negatively related to the volume of epilimnion, because with a larger volume there is relatively less proportion of total species abundances or element concentrations for sinking. For convenience, It has been assumed that the algal sinking rate is inversely proportional to the mixing layer depth $z_{m} . \quad D$ is the water exchange rate across the interface between epilimnion and hypolimnion and between the epilimnion and the inflow and outflow. We assume that there is a constant phosphorus concentration, $P_{i n}$, in the hypolimnion and in the inflow. Using the same reasoning as for algal sinking, we assume the water exchange is inversely proportional to $z_{m}$ [40]. Importantly, since algal organic carbon exudation is often a prime energy source for bacterial growth [6] and is known to depend on algal nutritional status [15], algal exudation of excess DOC as a function of nutrient limitation was explicitly modeled. To simplify the study of algal exudation on bacterial growth, in our model we assumed that algal DOC exudation is the only source of organic $\mathrm{C}$ for bacterial subsistence. We also assume that bacteria have a fixed stoichiometry [30], called "strict homeostasis" [34]. In addition, we assume that bacterial growth functions for carbon and phosphorus take the Monod form. Furthermore, we assume that bacteria take up the DOC and dissolved inorganic phosphorus (DIP) that they need.

Our comparison of the model with empirical results will focus on microcosm experiments con- 
ducted by Roberts and Howarth [33] to address two main predictions based on hypotheses of bacterial and phytoplankton resource limitation: (1) Bacteria contribute less than autotrophs to ecosystem respiration as trophic status increases. (2) If either light or nutrients are limiting, the percentage of ecosystem respiration accounted for by phytoplankton will decrease. The first prediction was tested through nutrient-fertilization of two microcosms and the second was examined in a factorial experiment involving three light levels and two nutrient levels in three microcosm experiments. To be able to compare our theoretical results with the microcosm data, we first need to derive an appropriate model incorporating the experimental conditions. To fulfill this, we modified model A1 in the following ways: (1) water exchange rate is negligible; (2) recycling is not negligible for a closed system, so algal recycling and bacterial recycling are added to the phosphorus concentration equation; (3) algal sinking velocity is negligible; (4) there is no grazing mortality rate for bacteria. We call the new model for a closed system A2 as an extension of the model A1 for an open system (see Figure 2).

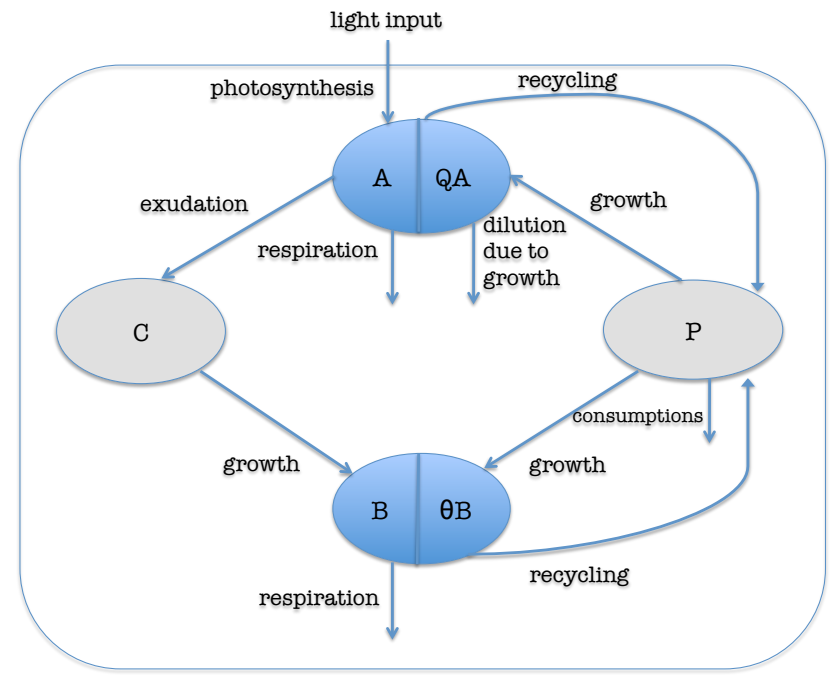

Figure 2: A scheme for the relation between bacteria and algae in a closed system. The mathematical model A2 was constructed following this network.

\section{Methods and Results}

The first qualitative analysis of model A1 proves that all feasible solutions of the bacteria-algae system are bounded in a region where the algal cell quota is between its minimum and maximum [40]. Furthermore, analysis of model A1 on a forward invariant set (solutions starting from this set stay in it for any forward time) shows that the system has three types of steady states: (1) 
extinction of both bacteria and algae, (2) bacteria extinction only, (3) coexistence. The basic reproductive number for bacteria, denoted by $R_{1}$, has been obtained by standard computation in [40]. It involves the average biomass of new bacteria produced by one unit of bacterial biomass during the bacterial life span in the epilimnion. To have a comprehensive understanding of model A1, a study of algae-only dynamics without bacteria $(B=0)$ was completed [40], reducing the system of five equations in A1 to three equations for algal density, algal cell quota and phosphorus concentration. This analysis shows that there can be two types of solutions for the corresponding system: (1) algal extinction $\left(E_{0}\right)$, and (2) positive steady state $\left(E^{*}\right)$. In addition, the basic reproductive number for algae, denoted by $R_{0}$, was found by standard computation in [40]. It accounts for the average amount of new algae produced by one unit of algae (measured in carbon content) during the algal life span in the epilimnion and serves as an indicator of algal viability. One of the main mathematical results regarding the algae-only system is the statement that, if $R_{0}<1$, then $E_{0}$ is locally and globally stable which is equivalent to saying that algae will die out but, if $R_{0}>1$, there exists a unique positive steady state $E^{*}$ such that algae uniformly persist. In fact, $R_{1}$ is an indicator for the bacterial viability when $R_{0}>1$. In addition, simulations were performed in [40] (Fig. 4.2.) for model A1 as light intensity varied from 0 to $1200 \mu \mathrm{mol}($ photons $) /\left(\mathrm{m}^{2} \cdot \mathrm{s}\right)$ and nutrient (phosphorus) availability changes from 0 to 150 $\mathrm{mgP} / \mathrm{m}^{3}$. These confirmed that there are three types of dynamics: (1) $R_{0}>1, R_{1}>1$, indicating the persistence of both species, (2) $R_{0}>1, R_{1}<1$, meaning the persistence of algae but the extinction of bacteria (in agreement with what we obtained; lower right corner of Figure 7), and (3) $R_{0}<1$, leading to the extinction of all species (also in consistent with left region of Figure 7). As this outcome suggests, high light intensity can negatively affect bacteria, even driving them to extinction due to competition with algae. Hence, these dynamical outcomes provide formal support for the view that the balance of light and nutrients is significant for aquatic ecosystem structure and process, in agreement with the "light:nutrient hypothesis" [35].

We start our comparisons for a closed system using model A2. We ran a MATLAB code simulating model A2 with the initial condition: $B(0)=5, A(0)=20, C(0)=100, Q(0)=0.004$, and $P(0)=T P-A(0) Q(0)-\theta B(0)$ (with units given in Table $I I$ ) [40] in which different values of TP (total phosphorus) were obtained from the experiments of Roberts and Howarth [33]. We also assumed the following parameter values (with units and sources given in Table $I I$ where the medians have been chosen for the values from the given ranges) for numerical simulations: 
$\mu_{A}=1, H=120, Q_{m}=0.004, l_{m}=0.1, \rho_{m}=0.2, Q_{M}=0.04, M=1.5, \mu_{B}=3, \mu_{r}=$ $0.2, k=0.0004, K_{b g}=0.3, K_{C}=100, K_{P}=0.06, \theta=0.1, z=0.5, r=0.5$, with all parameter values from [40] except $z$ which is from [33] . To obtain the bacterial percentage of total respiration from our model, we used the following formula $\left(\frac{a B}{a B+A}\right) 100$, where the parameter $a$ denotes the ratio of bacterial:algal respiration loss per unit biomass and the possible range for $a$ is computed by the ratio of $\mu_{r}$ to $l_{m}$. Note that the parameter $a$ is not a parameter in the model; $a$ is still a free parameter in data fitting, that is, a may be different in our fitting to different data sets. We fix all the parameters of the model to run the simulations.

We compared the bacterial percentage of total respiration as a function of TP for a fixed value $a=10$ with the data from two experiments reported by Roberts and Howarth [33] in Figures 3 and 4 by setting $\mathrm{I}_{\mathrm{in}}=325 \mu \mathrm{mol}\left(\right.$ photons) $/\left(\mathrm{m}^{2} \cdot \mathrm{s}\right)$ (average light intensity input) and running our code for $11 \mathrm{~d}$ and $8 \mathrm{~d}$, corresponding to their 2000 and 2001 microcosm experiments. Our model was successfully fit, with good match for $a=10$, according to least square error. These two microcosm experiments were part of nutrient enrichment gradient experiments to examine relative contribution of bacteria and algae in ecosystem respiration as nutrient availability changes. The experiments were conducted in a growth chamber on the Cornell University campus during August 2000 and September 2001. Water was collected in 25 5-gal carboys from $0.5 \mathrm{~m}$ below the surface in the middle of Skaneateles Lake, New York, U.S.A. (mean summer $[\mathrm{TP}] \sim 3.09$ $\mathrm{mgP} / \mathrm{m}^{3}$, mean summer [Chl a] 0.3-0.6 $\mu \mathrm{g}$ Chl a L ${ }^{-1}$; UFI 2003) on Aug 2000 and Sep 2001. Eight hundred milliliters of water from each of the 25 carboys was added to a total of 18 different 20-liter microcosm tanks (20 liters total added to each tank). After returning to the laboratory, microcosm tanks were covered (polycarbonate lids) and exposed to 14:10 h light:dark cycle in a growth chamber at constant $\mathrm{T}=22^{\circ} \mathrm{C}$ for $10 \mathrm{~d}$ (in 2000) or $8 \mathrm{~d}$ (in 2001). Growth chamber irradiance levels were set at a saturating level of $650 \mu \mathrm{mol}($ photons $) /\left(\mathrm{m}^{2} \cdot \mathrm{s}\right)$. Final nutrient levels were obtained via 10 (in 2000) or 7 (in 2001) day of daily liquid fertilizer additions of $\mathrm{N}\left(\mathrm{NaNO}_{3}\right)$ and $\mathrm{P}\left(\mathrm{H}_{3} \mathrm{PO}_{4}\right)$ at N:P molar ratio of 5:1 (in 2000) or 25:1 (in 2001). Triplicate microcosm tanks were exposed to one of six levels of nutrient addition over the duration of the experiments: 0.93 , $3.09,15.5,30.97,62$, or $154.85 \mathrm{mgP} / \mathrm{m}^{3}$. On day 11 (in 2000) and day 8 (in 2001) of each nutrient manipulation, water was collected to perform linearity test experiments of $\mathrm{O}_{2}$ consumption. In order to perform linearity test experiments to determine duration of dark incubations, water was collected from several of the experimental treatments 1 day prior to respiration incubations being 
performed. As a result of this test, microcosm tank samples were incubated between $12 \mathrm{~h}(154.85$ $\mathrm{mgP} / \mathrm{m}^{3}$ treatments $)$ and $36 \mathrm{~h}\left(0.93 \mathrm{mgP} / \mathrm{m}^{3}\right.$ in Skaneateles Lake water) [33].

In Figure 5, we explore this outcome by examining a time series for bacterial percentage of total respiration for $a=10$ for different values of TP. As the plot shows, bacterial percentage of total respiration does not decrease monotonically with TP when TP is elevated to $154.85 \mathrm{mgP} / \mathrm{m}^{3}$.

Figure 6 compares the model A2 predictions for bacterial percentage of total respiration with the three microcosm experimental data. We run our code when $I_{\text {in }}$ changes from 100 to 200 to $625 \mu \mathrm{mol}($ photons $) /\left(\mathrm{m}^{2} \cdot \mathrm{s}\right)$, and when nutrient level varies from high nutrient level $(\mathrm{TP}=62$ $\mathrm{mgP} / \mathrm{m} 3)$ to low nutrient level $(\mathrm{TP}=15.5 \mathrm{mgP} / \mathrm{m} 3)$ for $10 \mathrm{~d}$. Using least square error in our simulation, the best value for $a$ in the Skaneateles Lake experiments 1 and 2 was 2 and was 0.77 for the Cayuga Lake experiment. The experiments were conducted using the same growth chamber setup mentioned above reported by Roberts and Howarth [33] in two environments differing in phosphorus availability (high nutrient and low nutrient). The experiments used three levels of light availability (achieved by differential layering with 30 shade cloth) and two levels of nutrient fertilization (by daily additions of liquid fertilizer with N:P molar ratio of 25:1). The two levels of nutrient fertilization were based on target final TP concentrations corresponding to mesotrophic $\left(\mathrm{TP}=15.5 \mathrm{mgP} / \mathrm{m}^{3}\right)$ and eutrophic $\left(\mathrm{TP}=62 \mathrm{mgP} / \mathrm{m}^{3}\right)$ status. The three light levels corresponded to saturating conditions $\left(625 \mu \mathrm{mol}(\operatorname{photons}) /\left(\mathrm{m}^{2} \cdot \mathrm{s}\right)\right)$ and two degrees of light limitation $\left(\mathrm{I}_{\mathrm{in}}=100\right.$ and $\mathrm{I}_{\mathrm{in}}=200 \mu \mathrm{mol}($ photons $\left.) /\left(\mathrm{m}^{2} \cdot \mathrm{s}\right)\right)$. The first two experiments (beginning on June and August 2001) were again conducted using Skaneateles Lake as a source water, while the third (beginning on September 2001) used water collected from mesotrophic Cayuga Lake (mean summer $[\mathrm{TP}] \sim 15.5 \mathrm{mgP} / \mathrm{m}^{3}$, mean summer [Chl a] $\sim 5 \mu \mathrm{g} \mathrm{L}^{-1}$; UFI 2003). For all three experiments, water was collected from $0.5 \mathrm{~m}$ below the surface in carboys at a station in each lake (middle for Skaneateles Lake and at the Remote Underwater Sampling Station [RUSS] at the south end of Cayuga Lake). When water was brought back to the laboratory, three additional tanks were filled according to the procedure above. Water from these carboys was used to determine the initial respiration rates of bacteria, phytoplankton, and total plankton in Skaneateles and Cayuga Lake. Water was collected on day 8 of each experiment to perform linearity test experiments and on day 9 to determine bacterial, phytoplankton, and total plankton community respiration rates. 


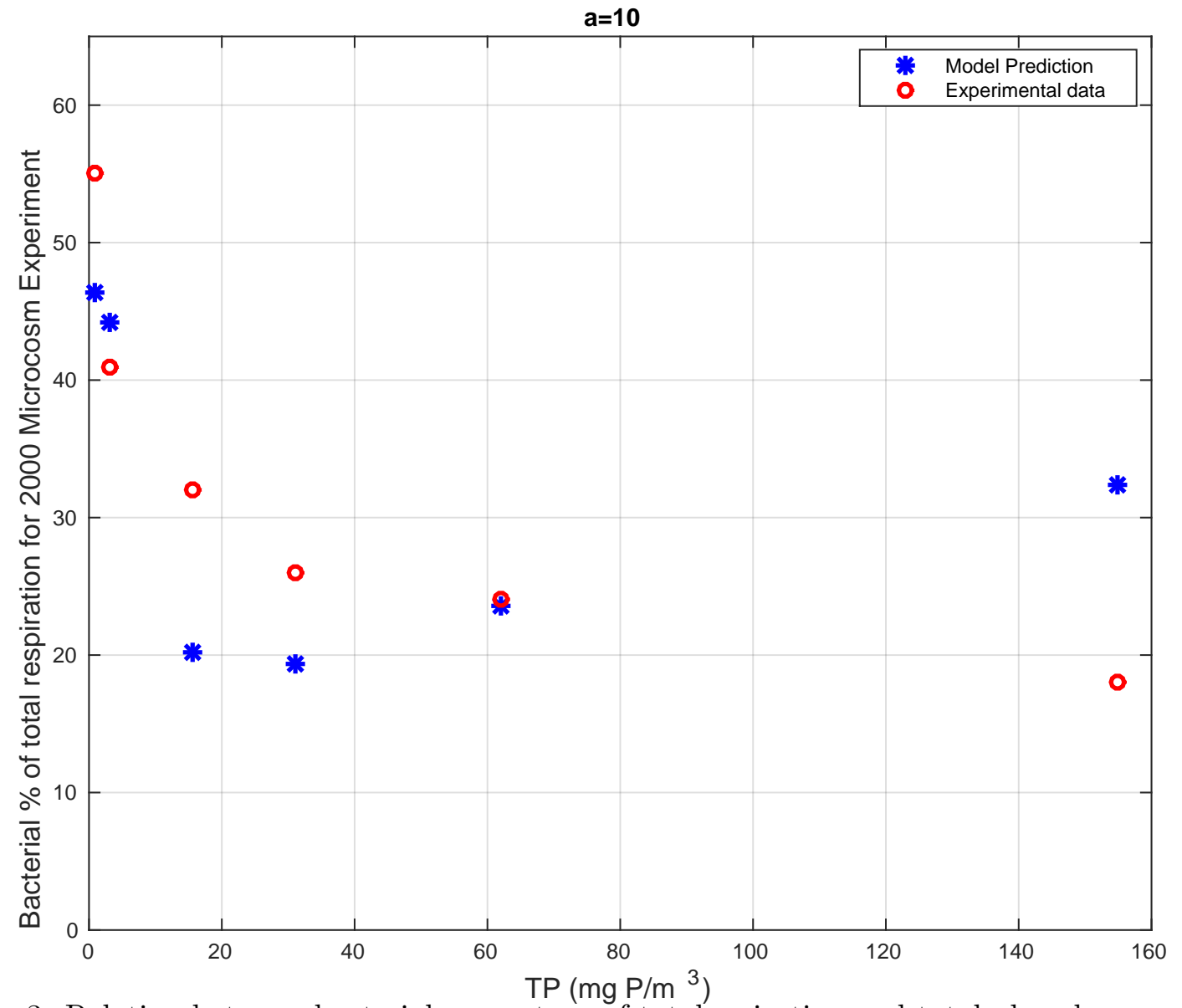

Figure 3: Relation between bacterial percentage of total resiration and total phosphorus concentration (TP) in 2000 microcosm experiment for a fixed ratio of bacterial:algal respiration loss per unit biomass, $a=10$, using model A2 with $\mathrm{I}_{\text {in }}=325 \mu \mathrm{mol}$ (photons) $/\left(\mathrm{m}^{2} \cdot \mathrm{s}\right)$ and $\mathrm{TP}=0.93,3.09$, $15.48,30.97,61.94$, and $154.85 \mathrm{mgP} / \mathrm{m}^{3}$ for 11 days with initial condition: $\mathrm{B}(0)=5, \mathrm{~A}(0)=20$, $\mathrm{C}(0)=100, \mathrm{Q}(0)=0.004$, and $\mathrm{P}(0)=\mathrm{TP}-\mathrm{A}(0) \mathrm{Q}(0)-\theta \mathrm{B}(0)$ compared with Fig.2. in Roberts and Howarth [33]. 


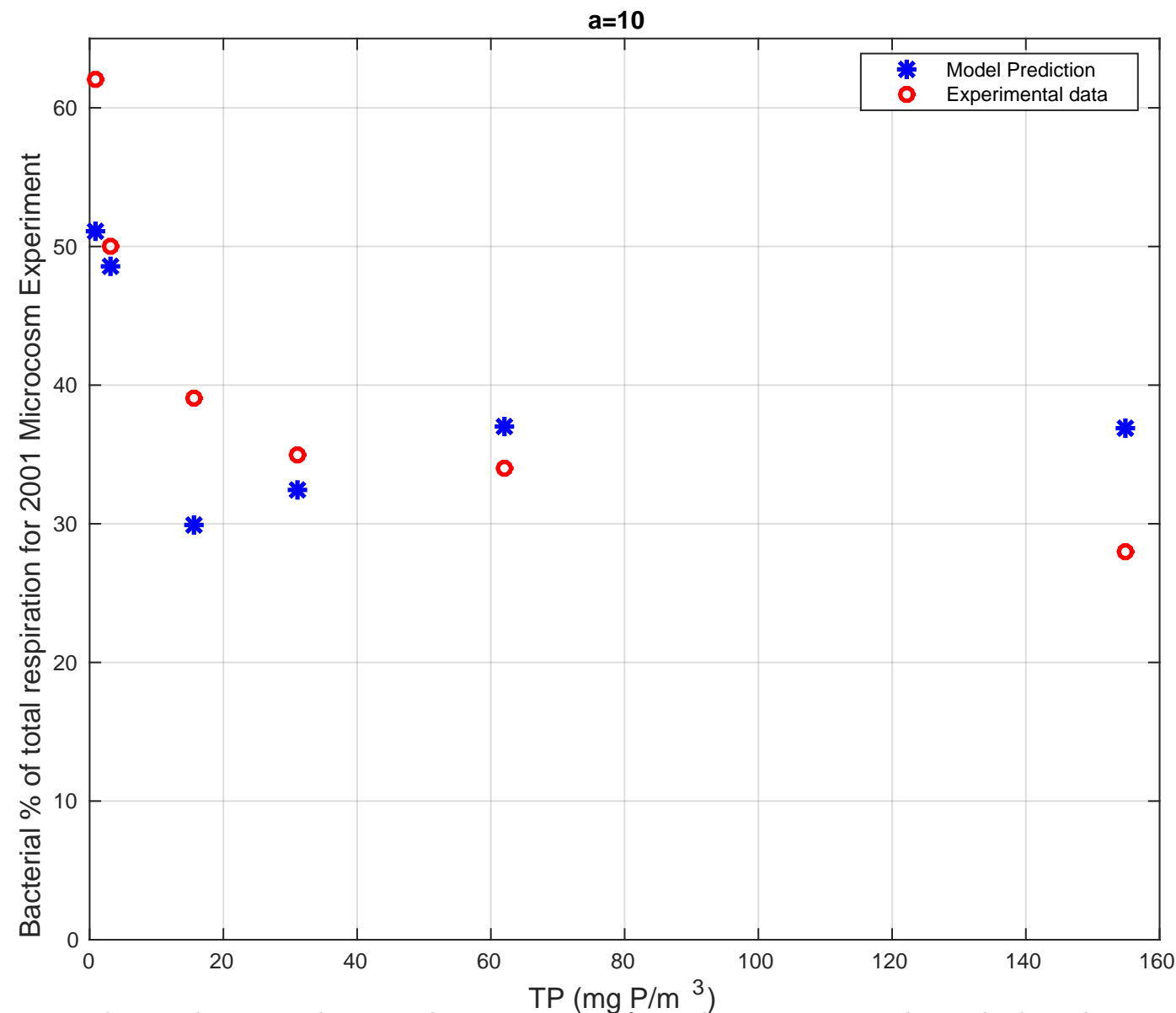

Figure 4: Relation between bacterial percentage of total resiration and total phosphorus concentration (TP) in 2001 microcosm experiment for a fixed ratio of bacterial:algal respiration loss per unit biomass, $a=10$, using model A2 with $\mathrm{I}_{\text {in }}=325 \mu \mathrm{mol}$ (photons) $/\left(\mathrm{m}^{2} \cdot \mathrm{s}\right)$ and $\mathrm{TP}=0.93,3.09$, $15.5,30.97,62$, and $154.85 \mathrm{mgP} / \mathrm{m}^{3}$ for 8 days with initial condition: $\mathrm{B}(0)=5, \mathrm{~A}(0)=20, \mathrm{C}(0)$ $=100, \mathrm{Q}(0)=0.004$, and $\mathrm{P}(0)=\mathrm{TP}-\mathrm{A}(0) \mathrm{Q}(0)-\theta \mathrm{B}(0)$ compared with Fig.2. in Roberts and Howarth [33]. 


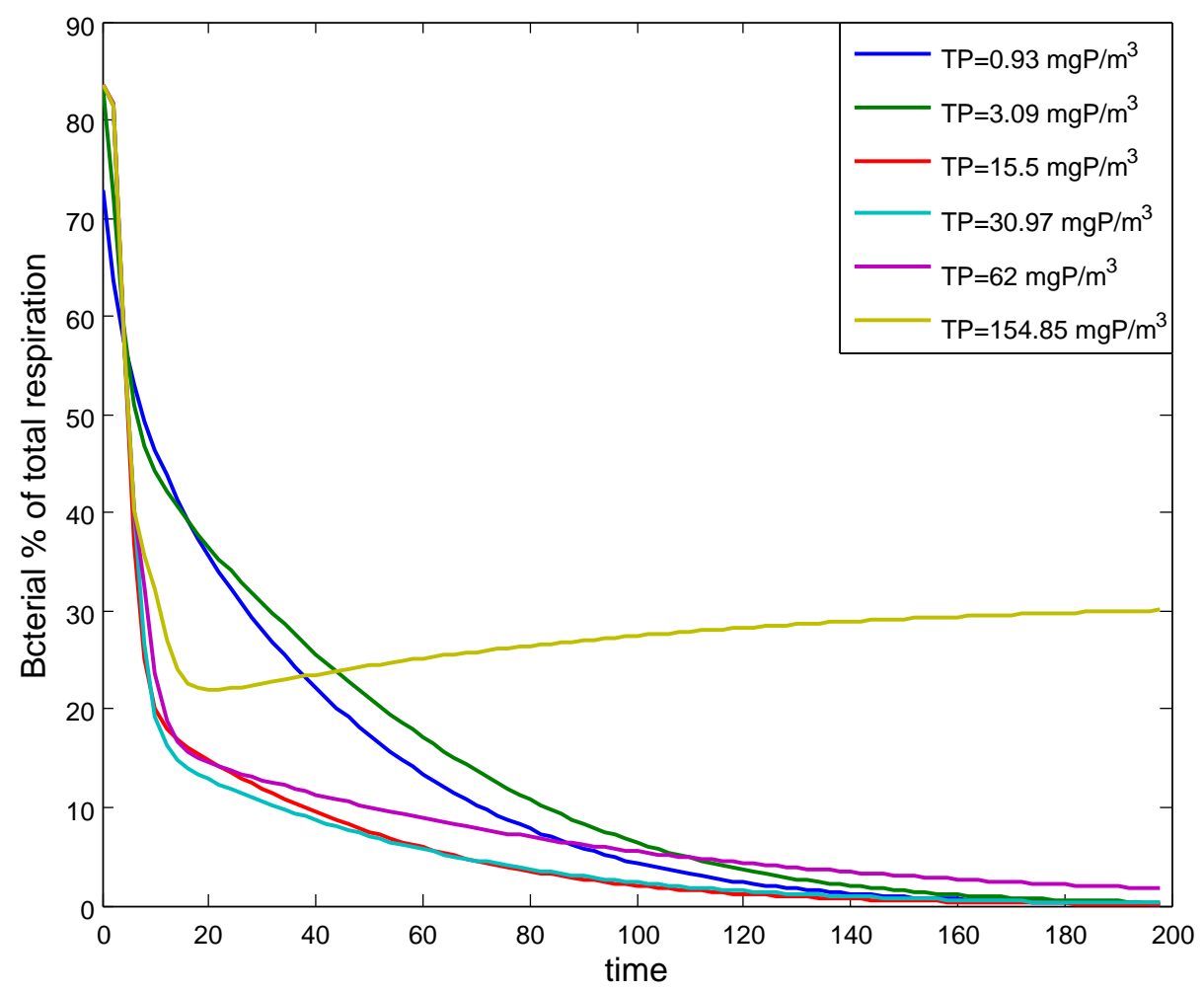

Figure 5: Times series of bacterial percentage of total respiration for different TP's corresponding to the values of TP examined in Roberts and Howarth [33] using model A2. 

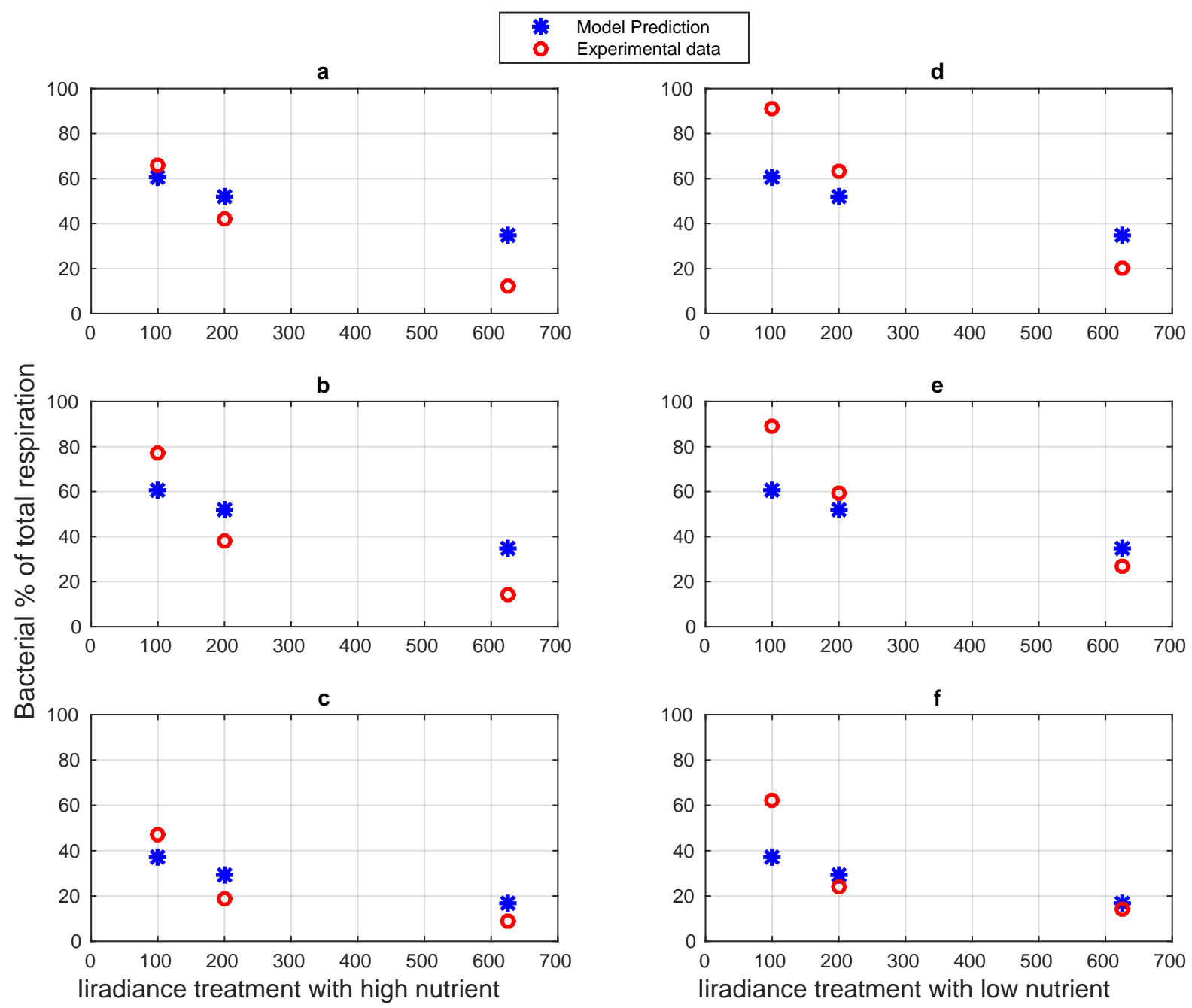

Figure 6: Model prediction fits the experimental data by obtaining the best value for ratio of bacterial:algal respiration loss per unit biomass $(a)$ for each experiment through least square error using model A2: a, and d are corresponding to Skaneateles Lake Experiment 1 with $a=2$, $\mathrm{b}$, and e to Skaneateles Lake Experiment 2 with $a=2$, c, and $\mathrm{f}$ to Cayuga Lake Experiment with $a=0.77$, respectively for 10 days with $\mathrm{I}_{\text {in }}=100, \mathrm{I}_{\text {in }}=200$, and $\mathrm{I}_{\text {in }}=625$, and with high nutrient level $\left(\mathrm{TP}=62 \mathrm{mgP} / \mathrm{m}^{3}\right)$ in the left panels and with low nutrient level $\left(\mathrm{TP}=15.5 \mathrm{mgP} / \mathrm{m}^{3}\right)$ in the right panels with initial condition: $\mathrm{B}(0)=5, \mathrm{~A}(0)=20, \mathrm{C}(0)=100, \mathrm{Q}(0)=0.004$, and $\mathrm{P}(0)$ $=\mathrm{TP}-\mathrm{A}(0) \mathrm{Q}(0)-\theta \mathrm{B}(0)$ compared with Fig.3. in Roberts and Howarth [33]. 
Our main findings are shown in Figure 7, which shows the prediction of the bacteria:algae ratio as light intensity input changes from 0 to $1200 \mu \mathrm{mol}($ photons $) /\left(\mathrm{m}^{2} \cdot \mathrm{s}\right)$ and phosphorus input changes from 0 to $1200 \mathrm{mgP} / \mathrm{m}^{3}$ given a fixed ratio of bacteria:algae respiration loss per unit biomass $(a=20)$ in steady state in open system (ponds) using model A1. In addition to the initial parameter value settings used in the first type of the data fitting (closed system), we assigned parameter values of $z=30, D=0.02, \nu=0.25, \mu_{g}=0.1$ (with units given in Table $I$ ) [40] to run our simulation.

At a given level of $\mathrm{P}$ input, as light availability increases, the bacterial share of respiration of total respiration increases to a maximum value, after which it decreases. In oligotrophic waters (low $\mathrm{P}$ ), the increasing region is small; hence, the percentage generally decreases as light increases.

These analyses indicate that bacteria need a larger nutrient supply to survive as light intensity increases from intermediate to high intensity conditions. At extra high light and low nutrient supply, bacteria have sufficient DOC to grow but they go extinct due to the nutrient limitation as the algal bloom caused by extra high light depletes nutrient. The high nutrient supply will relieve the nutrient limitation to bacterial growth. The maximum of relative bacterial biomass occurs at intermediate light supplies because there is a trade-off between carbon availability and phosphorus availability. Low light leads to the carbon limitation of bacterial growth (due to low algal abundance) while high light leads to the phosphorus limitation of bacterial growth (due to algal bloom). Thus, the relationship between bacteria and algae is commensalism when light input is low but shifts to competition when light input is high. However, when light availability is extremely low, both bacteria and algae go extinct (see the left extinction region of Figure 7). 


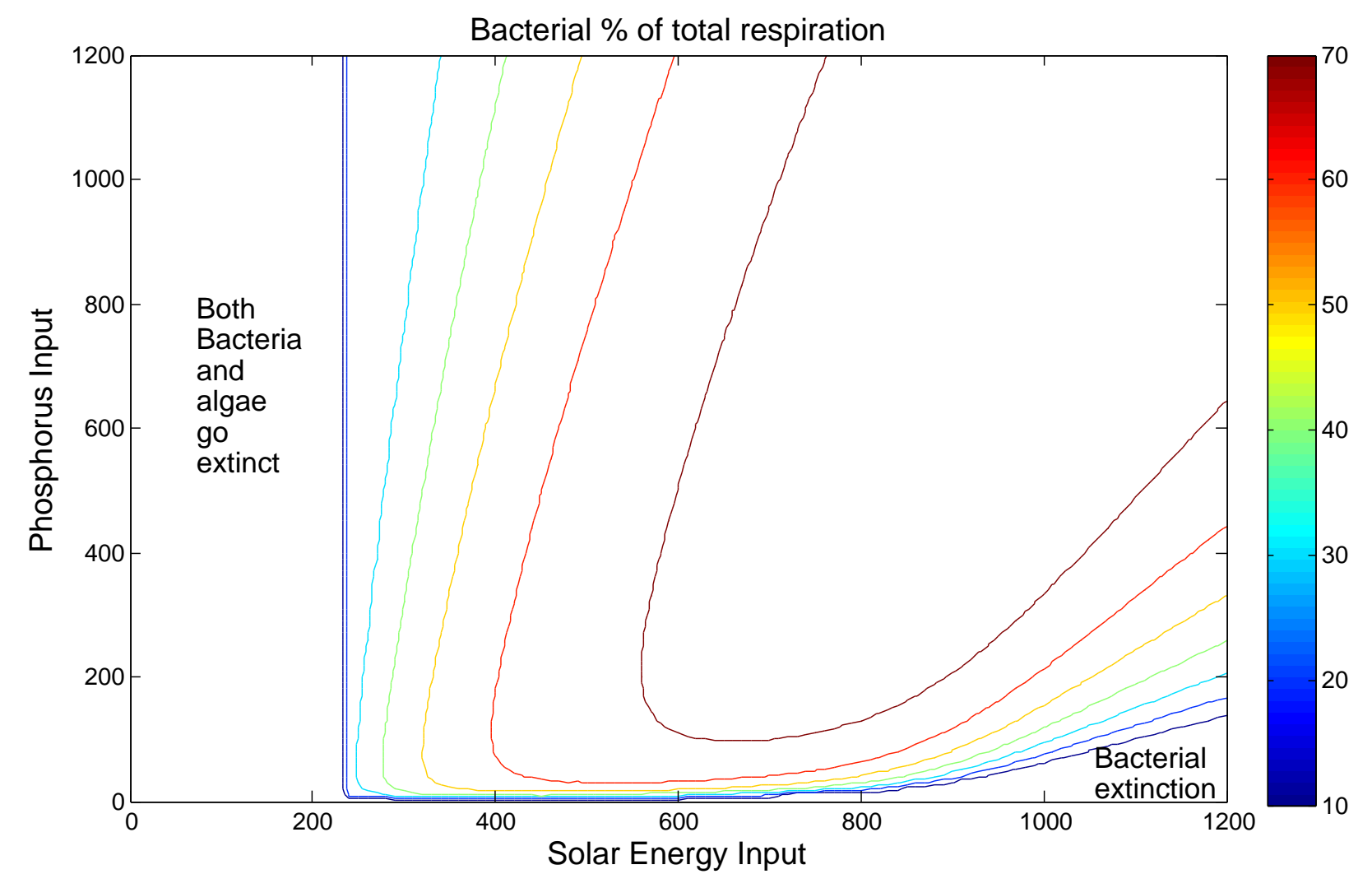

Figure 7: Bacteria:algae ratio predictions with fixed ratio of bacteria:algae respiration loss per unit biomass $(a=20)$ controlled by light and nutrient availability in steady state using model A1 with initial condition: $\mathrm{B}(0)=5, \mathrm{~A}(0)=20, \mathrm{C}(0)=100, \mathrm{Q}(0)=0.004$, and $\mathrm{P}(0)=0.1$. 


\section{Discussion}

Great progress in understanding and modelling ecological systems has been attained within last decade as a result of application of the theory of ecological stoichiometry [34] and taking into consideration of interactions between light and nutrient availability [11, 12, 23, 24, 25]. We employed a newly developed mathematical model [40], a hybrid of mechanistic and phenomenological derivations, to examine how light and nutrient availability regulate heterotrophic bacterial and algal abundances and the relative contributions of each to ecosystem respiration. The relative contribution to planktonic community respiration is proportional to the relative abundance of planktonic community given a fixed ratio of bacteria:algae respiration loss per unit biomass.

It is well known that bacterial percentage of total respiration changes with light as a function of trophic status $[2,32,33]$. In oligotrophic lakes, when light availability increases, we would expect to see a short stage of monotonic increase of the bacterial share of respiration of total respiration, after which the bacterial share will generally decrease. In eutrophic lakes, at a given level of $\mathrm{P}$ input we would expect to see a unimodal (hump-shaped) relation of bacteria:algae ratio as light intensity increases, as suggested in Figure 7. Gurung et al.'s [20] experiment also indicates that algae are relatively more dominant at higher light levels, which is also the oligotrophic case.

Our model indicates that bacteria need a greater nutrient supply to survive in very high light conditions: bacterial extinction region appears only in the lower right corner of Figure 7. This result explains Gurung et al.'s [20] finding that bacteria are limited mostly by P at intermediate $\mathrm{P}$ and at high light where the stoichiometric imbalance of C:P is greatest. Similarly, Cotner and Biddanda [8] also suggested that algae become better competitors for nutrients with increased light availability while bacteria may become more strongly nutrient-limited than under lower light conditions. In addition, Chrzanowski and Grover's [4] experiments provide evidence supporting the model result that bacterial growth was more often P-limited when light:nutrient ratio was high. All of these experimental findings are consistent with Figure 7, supporting the "light:nutrient hypothesis" in which Sterner et al. [35] hypothesized that the balance of energy (as light) and nutrient (as total phosphorus) shapes aquatic ecosystem structure and process, including the relative abundances of bacteria and algae.

To compare our model predictions with experiments in Roberts and Howarth [33], we assumed that mass-specific respiration rates for bacteria and algae are constant. Nevertheless, mass-specific 
respiration rates likely increase as the severity of nutrient limitation increases [33]. Regardless, this assumption may be sufficiently reasonable and simple enough to be used as a first approach. It would be worth allowing bacterial and algal respiration to be dependent on P-limitation in future models. The model may help in understanding planktonic dynamics during seasonal changes that alter light intensity. For example, the model implies that, as the epilimnion becomes shallower and thus increases the average light availability, algae may come to dominate the planktonic community, sequestering available nutrients in epilimnion, as has been suggested by Cotner and Wetzel [9]. However, our model indicates that this familiar observation is only true in oligotrophic waters (Figure 7).

Light intensity plays an important role in regulating biochemical and ecological processes in living organisms. Light intensity and subsequently temperature is a master variable controlling biochemical processes in organisms and its effects are exhibited on many organizational level in organisms and ecosystems. It has fundamental impact on chemical and biological reaction rates. Even though there has been substantial interest in the effect of light level on organismal and ecosystem metabolic processes, light intensity and thus temperature can also have key indirect effects on organisms mediated through impacts on biological stoichiometry. In addition to light level, nutrient availability also contributes to changes in the composition of planktonic ecosystems. We were able to mathematically demonstrate how a changing thermal environment and nutrient supply could result in shifts in planktonic community composition. Understanding the changes in community composition will allow us better predictions of annual ecosystem level processes and improve projections of the impacts of climate change in aquatic ecosystems.

\section{Acknowledgements}

We would like to thank J. P. Grover for his valuable comments and suggestions. H. Wang would like to acknowledge the support from NSERC, and J. J. Elser would like to acknowledge the support from NSF. 


\section{References}

1. S. A. Berger, S. Diehl, T. J. Kunz, D. Albrecht, A. M. Oucible, and S. Ritzer, (2006), Light supply, plankton biomass, and seston stoichiometry in a gradient of lake mixing depths, Limnol. Oceanogr. 51, 1898-1905.

2. B. Biddanda, M. Ogdahl, and J. Cotner, (2001), Dominance of bacterial metabolism in oligotrophic relative to eutrophic waters, Limnol. Oceanogr. 46, 730-739.

3. G. Bratbak and T. F. Thingstad, (1985), Phytoplankton-bacteria interactions: an apparent paradox? Analysis of a model system with both competition and commensalism, Marine Ecology - Progress Series 25, 23-30.

4. T.H. Chrzanowski and J. P. Grover, (2001), The light:nutrient ratio in lakes: a test of hypothesized trends in bacterial nutrient limitation, Ecology Letters. 4, 453-457.

5. C. T. Codeço and J. P. Grover, (2001), Competition along a spatial gradient of resource supply: A microbial experimental model, Am. Nat. 157, 300-315.

6. J. J. Cole, G. E. Likens, and D. L. Strayer, (1982), Photosythetically produced dissolved organic carbon: An important carbon source for planktonic bacteria, Limnol. Oceanogr. 27, $1080-1090$.

7. J. P. Connolly, R. B. Coffin, and R. E. Landeck (1992) in C. Hurst (Ed.), Modeling carbon utilization by bacteria in natural water systems, in Modeling the Metabolic and Physiologic Activities of Microorganisms, John Wiley, New York, pp. 249-276.

8. J. B. Cotner and B. A. Biddanda, (2002), Small players, large role: microbial influence on autoheterotrophic coupling and biogeochemical processes in aquatic ecosystems, Ecosystems $5,105-121$.

9. J. B. Cotner and R. G. Wetzel, (1992), Uptake of dissolved and inorganic phosphorus compounds by phytoplankton and bacterioplankton, Limnol. Oceanogr. 37, 232-243.

10. P. A. Del Giorgio, J. J. Cole, and A. Cimberlis, (1997), Respiration rates in bacteria exceed phytoplankton production in unproductive aquatic systems, Nature 385, 148-151. 
11. S. Diehl, (2002), Phytoplankton, light, and nutrients in a gradient of mixing depths: Theory, Ecology 83, 386-398.

12. S. Diehl, S. A. Berger, and R. Wöhrl, (2005), Flexible algal nutrient stoichiometry mediates environmental influences on phytoplankton and its abiotic resources, Ecology 86, 2931-2945.

13. M. R. Droop, (1974), The nutrient status of algal cells in continuous culture, J. Mar. Biol. Assoc. U.K. 54, 825-855.

14. M. R. Droop, (1983), 25 years of algal growth kinetics: A personal view, Bot. Mar. 26, 99-112.

15. J. J. Elser, P. Frost, M. Kyle, J. Urabe, and T. Andersen, (2002), Effects of light and nutrients on plankton stoichiometry and biomass in a P-limited lake, Hydrobiologia 481, 101-112.

16. J. J. Elser, M. Kyle, W. Makino, T. Yoshida, and J. Urabe, (2003), Ecological stoichiometry in the microbial food web: a test of the light:nutrient hypothesis, Aquat. Microb. Ecol. 31, $49-65$.

17. J. P. Grover, (2013), private communication.

18. J. P. Grover, (2000), Resource competition and community structure in aquatic microorganisms: experimental studies of algae and bacteria along a gradient of organic carbon to inorganic phosphorus supply, J. Plankton Res. 22, 1591-1610.

19. J. P. Grover, (2002), Stoichiometry, herbivory and competition for nutrients: simple models based on planktonic ecosystems, J. Theor. Biol. 214, 599-618.

20. T. B. Gurung, J. Urabe, and M. Nakanishi, (1999), Regulation of the relationship between phytoplankton Scenedesmus acutus and heterotrophic bacteria by the balance of light and nutrients, Aquat. Microb. Ecol. 17, 27-35.

21. D. O. Hessen, K. Nygaard, K. Salonen, and A. Vähätalo, (1994), The effect of substrate stoichiometry on microbial activity and carbon degradation in humic lakes, Environ. Int. 20, $67-76$.

22. A. J. Horne and C. R. Goldman (1994) Limnology 2nd ed, McGraw-Hill Co., New York. 
23. J. Huisman and F. J. Weissing, (1994), Light-limited growth and competition for light in well-mixed aquatic environments: an elementary model, Ecology 75, 507-520.

24. J. Huisman and F. J. Weissing, (1995), Competition for nutrients and light in a mixed water column: A theoretical analysis, Am. Nat. 146, 536-564.

25. C. A. Klausmeier and E. Litchman, (2001), Algal games: The vertical distribution of phytoplankton in poorly mixed water columns, Limnol. Oceanogr. 46, 1998-2007.

26. C. A. Klausmeier, E. Litchman, and S.A. Levin, (2004), Phytoplankton growth and stoichiometry under multiple nutrient limitation, Limnol. Oceanogr. 49, 1463-1470.

27. I. Loladze, Y. Kuang, and J. J. Elser, (2000), Stoichiometriy in producer-grazer systems: linking energy flow with element cycling, Bull. Math. Biol. 62, 1137-1162.

28. I. Loladze, (2002), Rising atmospheric $\mathrm{CO}_{2}$ and human nutrition: toward globally imbalanced plant stoichiometry?, TRENDS in Ecology and Evolution. 17, 457-461.

29. I. Loladze, Y. Kuang, J. J. Elser, and W. F. Fagan, (2004), Coexistence of two predators on one prey mediated by stoichiometry, Theor. Popul. Biol. 65, 1-15.

30. W. Makino, J. B. Cotner, R. W. Sterner, and J. J. Elser, (2003), Are bacteria more like plants or animals? Growth rate and resource dependence of bacterial C:N:P stoichiometry, Functional Ecology 17, 121-130.

31. Y. Nishimura, C. Kim, and T. Nagata, (2005), Vertical and seasonal variations of bacterioplankton subgroups with different nucleic acid contents: possible regulation by phosphorus, Applied and Environmental Microbiology 71, 5828-5836.

32. M. L. Pace and J. J. Cole, (2000), Effects of whole lake manipulations of nutrient loading and food web structure on planktonic respiration, Can. J. Fish. Aquat. Sci. 57, 487-496.

33. B. J. Roberts and R. W. Howarth, (2006), Nutrient and light availability regulate the relative contribution of autotrophs and heterotrophs to respiration in freshwater pelagic ecosystems, Limnol. Oceanogr. 51, 288-298.

34. R. W. Sterner and J. J. Elser (2002) Ecological Stoichiometry - The biology of elements from molecules to the biosphere, Princeton University Press. 
35. R. W. Sterner, J. J. Elser, E. J. Fee, S. J. Guildford, and T. H. Chrzanowski, (1997), The light:nutrient ratio in lakes: the balance of energy and materials affects ecosystem structure and process, Am. Nat. 150, 663-684.

36. T.F. Thingstad and B. Pengerud, (1985), Fate and effect of allochthonous organic material in aquatic microbial ecosystems. An analysis based on chemostat theory. Mar. Ecol. Prog. Ser. $21,47-62$.

37. J. Urabe and R. W. Sterner, (1996), Regulation of herbivore growth by the balance of lightand nutrients, Proc. Natl. Acad. Sci. USA, 93, 8465-8469.

38. O. Vadstein, (2000), Heterotrophic, planktonic bacteria and cycling of phosphorus. Phosphorus requirements, competitive ability, and food web interactions, Adv. Microb. Ecol. 16, pp. $115-167$

39. P.M. Vitousek, (1994), Beyond global warming- ecology and global change, Ecology 75, 18611876.

40. H. Wang, H. L. Smith, Y. Kuang, and J. J. Esler, (2007), Dynamics of stoichiometric bacteriaalgae interactions in the epilimnion, SIAM J. Appl. Math. 68, 503-522.

41. F. J. Wrona, T. D. Prowse, J. D. Reist, J. E. Hobbie, L. M. J. Levesque, and W. F. Vincent, (2006), Climate change effects on aquatic biota, ecosystem structure and function. Ambio 35, $359-369$ 


\section{Appendix}

A1. Mathematical model for lakes or ponds:

$$
\begin{aligned}
& \frac{d A}{d t}=\underbrace{\mu_{A} A\left(1-\frac{Q_{m}}{Q}\right) \frac{1}{z_{m}} \int_{0}^{z_{m}} \frac{I(s, A)}{I(s, A)+H} d s}_{\text {algal growth rate }}-\underbrace{l_{m} A}_{\text {respiration }}-\underbrace{\frac{\nu+D}{z_{m}} A}_{\text {sinking and exchange }} \\
& \frac{d Q}{d t}=\underbrace{\rho(Q, P)}_{\text {replenishment }}-\underbrace{\mu_{A} Q\left(1-\frac{Q_{m}}{Q}\right) \frac{1}{z_{m}} \int_{0}^{z_{m}} \frac{I(s, A)}{I(s, A)+H} d s}_{\text {dilution due to growth }} \\
& \frac{d P}{d t}=\underbrace{\frac{D}{z_{m}}\left(P_{\text {in }}-P\right)}_{\text {Pin and exchange }}-\underbrace{\rho(Q, P) A}_{\text {algae P consumption }}-\underbrace{\theta \mu_{B} B f(P) g(C),}_{\text {bacteria P consumption }} \\
& \frac{d B}{d t}=\underbrace{\mu_{B} B f(P) g(C)}_{\text {bacterial growth }}-\underbrace{\left(\mu_{r}+\mu_{g}\right) B}_{\text {respiration and grazing }}-\underbrace{\frac{D}{z_{m}} B}_{\text {exchange }} \\
& \frac{d C}{d t}=\underbrace{\mu_{A} A \frac{Q_{m}}{Q} \frac{1}{z_{m}} \int_{0}^{z_{m}} \frac{I(s, A)}{I(s, A)+H} d s}_{\text {DOC exudation from algae }}-\underbrace{\frac{1}{r} \mu_{B} B f(P) g(C)}_{\text {DOC consumption by bacteria }}-\underbrace{\frac{D}{z_{m}} C}_{\text {exchange }} .
\end{aligned}
$$

A2. Mathematical model for microcosms:

$$
\begin{aligned}
& \frac{d A}{d t}=\underbrace{\mu_{A} A\left(1-\frac{Q_{m}}{Q}\right) \frac{1}{z_{m}} \int_{0}^{z_{m}} \frac{I(s, A)}{I(s, A)+H} d s}_{\text {algal growth rate }}-\underbrace{l_{m} A,}_{\text {respiration }} \\
& \frac{d Q}{d t}=\underbrace{\rho(Q, P)}_{\text {replenishment }}-\underbrace{\mu_{A} Q\left(1-\frac{Q_{m}}{Q}\right) \frac{1}{z_{m}} \int_{0}^{z_{m}} \frac{I(s, A)}{I(s, A)+H} d s}_{\text {dilution due to growth }}, \\
& \frac{d P}{d t}=\underbrace{l_{m} A Q}_{\text {algal recycling }}+\underbrace{\mu_{r} \theta B}_{\text {bacterial recycling }}-\underbrace{\rho(Q, P) A}_{\text {algae P consumption }}-\underbrace{\theta \mu_{B} B f(P) g(C),}_{\text {bacteria P consumption }} \\
& \frac{d B}{d t}=\underbrace{\mu_{B} B f(P) g(C)}_{\text {bacterial growth }}-\underbrace{\mu_{r} B}_{\text {respiration }} \\
& \frac{d C}{d t}=\underbrace{\mu_{A} A \frac{Q_{m}}{Q} \frac{1}{z_{m}} \int_{0}^{z_{m}} \frac{I(s, A)}{I(s, A)+H} d s}_{\text {DOC exudation from algae }}-\underbrace{\frac{1}{r} \mu_{B} B f(P) g(C)}_{\text {DOC consumption by bacteria }}
\end{aligned}
$$


Here,

$f(P)=\frac{P}{K_{P}+P}$ is bacterial growth function for phosphorus,

$g(C)=\frac{C}{K_{C}+C}$ is bacterial growth function for carbon,

$I(S, A)=I_{\text {in }} \exp \left[-\left(k A+K_{b g}\right) s\right]$ is the light intensity at the depth $s$ of a water column with algal abundance $A$,

$\rho(Q, P)=\rho_{m}\left(\frac{Q_{M}-Q}{Q_{M}-Q_{m}}\right) \frac{P}{M+P}$ is algal phosphorus uptake rate. 


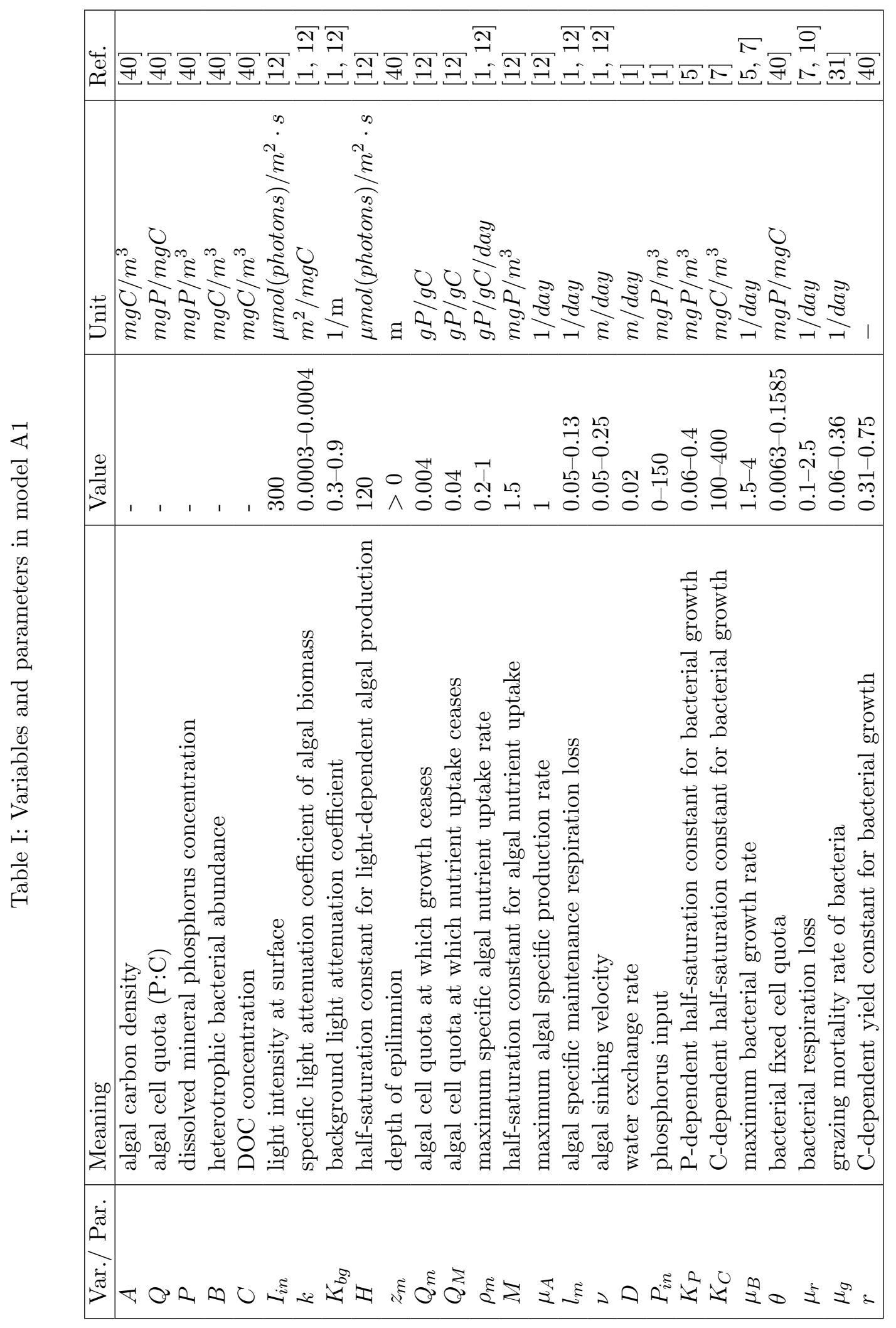




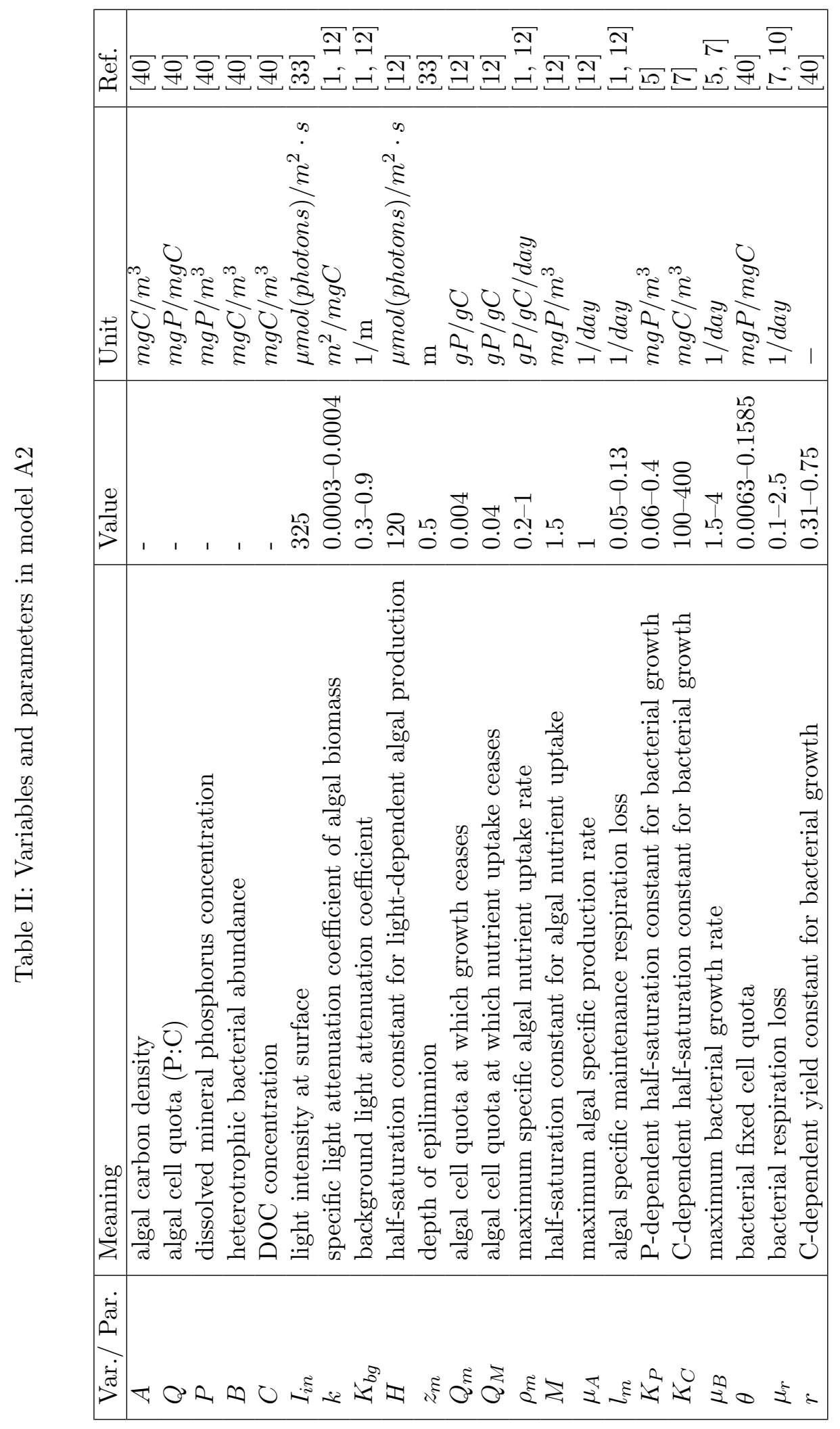

